time the off-season arrives that infection dies out completely, presumably because the few susceptible rats then surviving are so scattered as to render it difficult or impossible for infected fleas to perpetuate the epizootic by passing from one rat to another.

Now the few towns or villages in which plague infection is likely to persist through the off-season can be detected with a little practice and with the aid of certain "charts"; and the authors' scheme was to reinforce the natural tendency of plague infection to die out by further reducing the rat population in these centres by poisoning or some other means of destruction. Any future epidemics which might occur within the experimental area would then be entirely dependent on re-importation from without.

The experiment was carried out in those places, fifty in number, which were considered likely to carry over the infection from one season to the next (of the 407 places excluded as not likely to carry over, only three, in fact, continued to harbour plague throughout the off-season). The agent of destruction was the "Punjab Rat-exterminator."

Briefly, the experiment was not a success; and since there was practically no failure in "spotting" the places likely to carry over, since, too, the authors are able to conclude that an epidemic of plague in this area is far more dependent on off-season centres of plague infection within the area than on importation of infection from without, it follows that failure was attributable largely to the inadequacy of the methods of rat-destruction.

The authors, therefore, determined to concentrate on the improvement of methods of rat-destruction. Traps were found to vary considerably in efficiency, and can be much improved by attention to certain apparently trivial details of construction. Hydrocyanic acid gas, in general a useful method of destroying rats and their fleas, would be of little practical value for the present purpose unless some method could be devised of rendering Indian houses more airtight while they are being fumigated.

The most efficient and suitable rat poison, of all those experimented with, was barium carbonate. Three grains is a suitable dose; this quantity mixed with four times its weight of food material does not diminish the amount of the latter consumed by the rat; the Punjab rat-exterminator-a phosphorous compound-was, however, found to be actively repulsive to the rat. Barium carbonate, again, was found to be twice as poisonous as the Punjab compound, and a lethal dose costs only one-sixtieth as much as one of the latter substance. Arsenious acid would be the most suitable substitute for the barium carbonate if this were not available. Bajri flour is the best vehicle.

The authors' experiments are as yet incomplete, and have, so far, been carried out only in the laboratory; they hope, however, to amplify them and confirm thern under more natural conditions. When, armed with their new knowledge, they return to the practical work of rat destruction, we hope that the problem of plague extermination will be advanced one stage nearer a solution.

\section{The Carbonisation of Peat in Vertical Gas Retorts.} $T$ HE programme of work undertaken by the Fuel utilisation of machine-won peat, and a report has been issued giving the results of the first series of experiments on the carbonisation of peat in vertical gas retorts with steaming. This material was macerated in 1920 , spread on the bog at Turraun, air dried and harvested there, and early in $192 \mathrm{I}$ a hundred tons were sent to the Fuel Research Station, primarily for experiments upon its use in carbonisation and boiler firing.

The peat as received at East Greenwich consisted of hard blocks with a density rather under $I$, or about twice that of the ordinary hand-cut sods made on the same bog. The water content, about 25 per cent., was neduced on storage under cover to ${ }_{17}$ per cent. These peat blocks are reported to have lent themselves admirably, after suitable treatment, to carbonisation in vertical retorts at temperatures between $750^{\circ}$ and $850^{\circ}$ C., and also in steel retorts at $55^{\circ}$ and $600^{\circ}$ C., the resultant charcoal being ideal fuel for suction gas producers. The vertical retort setting for carbonisation was of the Glover-West design, somewhat modified, as used in the tests already reported on the steaming process for gas-making from coal. Some difficulties were encountered, mainly of a mechanical order. The peat was not suitable for feeding with the ordinary arrangement, and the high percentage of dust which it contained on crushing gave trouble from its being carried forward into the gas main and forming a thick mass with the tar. A through-put of three tons of peat per retort was maintained.

After supplying sufficient heat for carbonisation of the peat there were for disposal from each ton of peat 7940 cubic feet of gas of 325 B.Th.U., I2.6 gallons of tar, $95^{\frac{1}{2}}$ gallons of liquor of $3.6 \mathrm{oz}$. strength per ton, and $5.4 \mathrm{cwt}$. of charcoal. The liquor was weak, and its quantity corresponded with some $27 \mathrm{lb}$. of ammonium sulphate per ton. The peat gas, which was very dense, contained is to $I_{7}$ per cent. carbon dioxide, but it burned with a satisfactory flame though "with only slight luminosity. A feature of the gas was the heavy sickly odour which it gave out on combustion. The light spirit amounted to nearly two gallons per ton of peat.

The report is supplemented by eight tables in which various thermal and chemical data are collected, including analyses of the peat and its products, and an examination of the tar oils.

J. W. C.

\section{University and Educational Intelligence.}

AbERDEEN.-A special examination for ex-Service students has resulted in the capping of twenty-eight graduates in medicine-M.B. and Ch.B. degrees-of whom four are with distinction. The informal graduation ceremony was conducted on December 24 by the Vice-Chanceltor, Principal the Rev. Sir George Adam Smith.

LEEDs.-The Council of the University has conferred upon. Mr. W. E. H. Berwick the appointment of reader in mathematical analysis. Mr. Berwick has been lecturer in the department of mathematics of the University since October, 1920.

THE following elections to the scholarships in commerce have been made by the University of London :Sir Edward Stern scholarships of $50 l$. a year for two years, W. W. Hewett and K. P. Rush. Sir Ennest Cassel scholarships of the value of not less than $200 l$. for the study of commerce in foreign countries, C. E. Benzecry, W. F. Crick, T. A. Hooker, and F. W Taylor.

NO. 2722 , VOL. IO8] 